\title{
Harnessing science, technology and innovation for sustainable development
}

Science, Technology and Innovation (STI) play a critical role in fostering sustainable development which encompasses the core elements of economic growth, social equity and environmental protection. STI is a Sustainable Development Goal (SDG) on its own, as per UN's 2030 Agenda for Sustainable Development. SDG-9, which aims to build resilient infrastructure, promotes inclusive and sustainable industrialisation and foster innovation. Specifically, SDG-Target 9.5 envisages enhancing scientific research and upgrading the technological capabilities of industrial sectors in all countries, particularly in developing countries.

Until around the 1990s, it was widely believed that economic growth, measured in terms of Gross Domestic Product (GDP), was determined by land, labour, capital and productivity. Since then, it has become increasingly evident that enhancement of human capital in the form of knowledge inputs could lead to develop new technologies and innovations, and thereby, to raise productivity and in turn, GDP growth. In recent times, STI have enabled fast growing economies across the world to diversify their production of goods and services into new ventures, particularly in high-tech manufacturing, that generate higher value added outputs. The benefits accrued to the society from such transformations are manifold, including productivity improvement, faster economic growth, employment creation, export growth, poverty reduction, high living standards and better quality of life.

While Sri Lanka has graduated to the upper-middle income category this year, as per the World Bank's country ranking, her GDP growth has slowed down to less than 3 percent per annum at present. This growth setback could be largely attributed to the failure to expand the country's production capacity by adopting technology and innovation through a knowledge-based economy, which would have otherwise propelled exportled growth.

Therefore, in the context of today's globally integrated and competitive knowledge-based economy, it is critically important for an emerging economy like Sri Lanka to build up STI capacities at the firm, farm, industrial and national levels so as to overcome her production constraints, and thereby to improve the living conditions of the people. In this regard, it is essential to evolve a knowledge economy that creates, disseminates and uses knowledge to be competitive in today's increasingly integrated global market.

STI must contribute not only to economic growth but also to social inclusiveness and environmental protection, as mentioned earlier. This means that the benefits emanating from technology and innovation must be shared by all, particularly by the poor segments of the population, while safeguarding the natural environment for future generations.

Thus, it is essential to give high priority to formulate STI policies, in consultation with the private sector and other stakeholders, towards creating synergies between economic growth, social equity and environmental protection. Accordingly, the National Science Foundation (NSF), as the apex body mandated to serve and strengthen the Science and Technology (S\&T) sector in Sri Lanka, facilitates capacity building, infrastructure development, technology transfer, knowledge creation and sharing in all fields of S\&T to improve the quality of life of the people.

Sirimevan Colombage 